\title{
BORGES Y TZINACAN
}

\author{
POR \\ NICOLAS EMILIO ALVAREZ \\ Wayne University, Detroit
}

Los mejores cuentos de Borges se caracterizan por la densidad e imbricación de múltiples elementos narrativos y planos de significación dentro de un espacio lingüístico óptimo. Es preciso aceptar que «la mayor imposibilidad de las lecturas de los cuentos de Borges es precisamente la superposición de los varios niveles que juegan, ellos mismos, en distintos niveles del texto» ${ }^{1}$. Todo ello, a pesar del número exiguo de posibilidades narrativas que Borges ha alegado: "el número de fábulas o de metáforas de que es capaz la imaginación de los hombres es limitado» ${ }^{2}$. Estas pocas fábulas han de entenderse, sin embargo, a manera de átomos narrativos de compleja composición atómica y molecular. Un ejemplo de esto lo es «La escritura del dios» (El Aleph), cuento central de la narrativa borgeana.

Parte nuestro estudio de una premisa básica claramente sentada por Alberto C. Pérez: «'La escritura del Dios' es un relato estructurado, casi exclusivamente, alrededor de símbolos. Posee una brevísima anécdota que sirve de pretexto para introducir los símbolos y metáforas mágicas sobre los que está construido el andamiaje de la ficción» ${ }^{3}$. No sólo nos parece esto un hecho incontrovertible, sino que el relato envuelve un núcleo teológico-metafísico fundamentado en un acontecimiento histórico con-

: Nicolás Rosa, «Borges o la ficción laberíntica», Nueva novela latinoamericana. tomo II: La narrativa argentina actual, compilación de Jorge Lafforgue (Buenos Aires: Paidós, 1972), p. 170.

${ }^{2}$ Jorge Luis Borges, «Epílogo» a Otras inquisiciones, Obras completas. 19231972 (Buenos Aires: Emecé, 1974), p. 775. Citaremos por esta edición, poniendo el título del libro y la página correspondiente entre paréntesis; para «La escritura del dios» bastará con citar la página.

${ }^{3}$ Realidad y suprarrealidad en los cuentos fantásticos de Jorge Luis Borges (Miami: Ediciones Universal, 1971), p. 143. 
creto e informado esencialmente por doctrinas aristotélicas y platónicas y por la influencia de la cosmogonía maya y el cabalismo. Nos proponemos dejar documentadas tales fuentes esenciales del relato y sacar las conclusiones del caso. Con ello hemos procurado apartarnos de una serie de alegaciones previas que podrían desviar la índole de este análisis. Dejaremos plenamente establecida la fuente histórica del protagonista Tzinacán - que no se trata de un sacerdote azteca, como se ha afirmadoy la influencia intrínseca de la Cábala y del Popol-Vuh.

Previamente, debemos apuntar un fundamento estético de importancia capital en el cuento. Así como Borges ha demostrado buen conocimiento de la filosofía platónica y, a la vez, se ha estudiado su influencia en la obra borgeana ${ }^{4}$, nos parece igualmente innegable la influencia aristotélica en este pronunciamiento del escritor: «el arte, siempre, opta por lo individual, lo concreto: el arte no es platónico» ${ }^{5}$. Este credo estético demuestra una concordancia palpable con el juicio de S. H. Butcher sobre la concepción de la poesía que Aristóteles dejó expuesta en su Poética: «The aim of poetry is to represent the universal through the particular, to give a concrete and living embodiment of a universal truth» ${ }^{6}$. Asimismo, Aristóteles dejó consignados unos principios estéticos cuyas resonancias todavía perduran; basta con mencionar catarsis, mimesis, unidad. Es así que un estudioso contemporáneo de la Poética haya afirmado: "The Poetics is best understood as a treatise on fiction" ${ }^{7}$. Por su parte, Borges ha dejado constancia en varios lugares de su obra de poseer un amplio conocimiento del aristotelismo, y, en efecto, habrá de constatarse la existencia en el relato de algunas categorías aristotélicas del arte ${ }^{8}$.

${ }^{4}$ Véanse Carter Wheelock, The Mythmaker: A Etudy of Motif and Symbol in the Short Stories of Jorge Luis Borges (Austin: Univ. of Texas Press, 1969), pp. 6970, 156-157, 163-164, passim; Ana María Barrenechea, Borges, The Labyrinth Maker, traducción de Robert Lima (New York: Univ. Press, 1965), pp. 114-116, passim.

${ }^{5}$ Luis Harss y Barbara Dohman, «Jorge Luis Borges o la consolación por la filosofía», Los Nuestros (Buenos Aires: Sudamericana, 1969), p. 151.

${ }^{6}$ Aristotle's Theory of Poetry and Fine Art, Critical Text and Translation of The Poetics (1894; New York: Dover Publications, 1951), p. 192. Véanse pp. 172173.

${ }^{7}$ L. J. Potts, Aristotle on the Art of Fiction, English trans. of Aristotle's Poetics (Cambridge: Cambridge University Press, 1953), p. 9.

${ }^{8}$ En 1932, al escribir «Los avatares de la tortuga», Borges acudió a una traducción de la Metafísica (Discusión, p. 255); cuatro años después, en «La metáfora», se refirió a la Retórica (Historia de la eternidad, p. 382); y a la Poética se ha referido en «El pudor de la historia» (Otras inquisiciones, p. 754). Ya en términos contrastantes, Borges se ha expresado así: "Observa Coleridge que todos los hombres nacen aristotélicos o platónicos. Los últimos intuyen que las ideas son realidades; los primeros, que son generalizaciones; para éstos, el lenguaje no es otra cosa 
«La escritura del dios» se funda en el hecho histórico de la conquista de Guatemala por Pedro de Alvarado, durante la cual la capital de los quiché fue incendiada y las restantes tribus de la región fueron sometidas por los conquistadores españoles ${ }^{9}$. El acaecimiento histórico tiene implicaciones fundamentales para la plasmación del relato, ya que además de impartirle verosimilitud y concreción, determina la época y el lugar de la acción y propone a la vez ciertos móviles de conducta. De modo que, a la par de crear una literatura basada en la Literatura, Borges también crea su literatura de la Historia, la cual, naturalmente, él amolda de acuerdo con la intención novelesca. Sobre esta base histórica eficacísima, la narración se concentra en las experiencias mentales y místicas que le sobrevienen a Tzinacán en el aislamiento de su celda, una vez que Pedro de Alvarado lo hubo hecho prisionero luego de incendiar la pirámide de Qaholom, de la cual Tzinacán era su mago y sacerdote. Borges convierte a Tzinacán en el protagonista y narrador en primera persona del relato con el propósito de efectuar un afianzamiento mayor entre el plano histórico aludido y el literario, haciendo que la narración adquiera más visos de crónica que de cuento, género aquél propio de la época de la Conquista. Con lo cual Borges reforzó su intento por estamparle un sello de veracidad histórica a todo el relato.

Hemos aludido a la historicidad de Pedro de Alvarado. Conviene señalar asimismo que la figura de Tzinacán se asentó igualmente en una fuente histórica concreta. De su incursión por tierras de los mayas, Bernal Díaz del Castillo dejó constancia en su Historia verdadera de la conquista de la Nueva España: "Y luego vamos camino del asiento de la ciudad de Guatemala, la vieja, donde solían estar los caciques que se decían Zinacán y Sacachul, y antes de entrar en la ciudad estaba una barranca muy honda, y aguardándonos los escuadrones de guatemaltecas para no dejarnos pasar, y les hicimos ir con la mala ventura, y pasamos a dormir en la ciudad; y estaban los aposentos y casas tan buenas y de tan ricos edificios, en fin, como de caciques que mandaban todas las provincias comarcales» ${ }^{10}$. Queda verificada históricamente la existencia de un poderoso cacique quiché nombrado Zinacán, durante el período en que Pedro de Al-

que un sistema de símbolos arbitrarios; para aquéllos, es el mapa del universo. El platónico sabe que el universo es de algún modo un cosmos, un orden; ese orden, para el aristotélico, puede ser un error o una ficción de nuestro conocimiento parcial» (Otras inquisiciones, p. 745).

${ }^{9}$ Véase Irwin R. Blacker y Harry M. Rosen, The Golden Conquistadores (Indianapolis: Bobbs-Merrill, 1960), pp. 189-215.

${ }^{10}$ Historia verdadera de la conquista de la Nueva España, Introd. y notas por J. Ramírez Cabañas (México, D. F.: Ed. Pedro Robredo, 1939), III, 117-118. 
varado dominó a los mayas. Borges transformó la figura del cacique en sacerdote para dotarle del marco teológico imprescindible, de acuerdo con el argumento que él se proponía narrar. Y empleó para el nombre del sacerdote una grafía quiché que lo distingue aún más de la española.

En consonancia con el origen maya de Tzinacán, y de conformidad con su calidad de sacerdote y mago, se entiende entonces que durante la visión mística éste señale: "Vi los orígenes que narra el Libro del Común. Vi las montañas que surgieron del agua, vi los primeros hombres de palo, vi las tinajas que se volvieron contra los hombres, vi los perros que les destrozaron las caras» (599). Del Popol-Vuh o Libro del Común proceden directamente cada una de estas alusiones: «Vi las montañas que surgieron del agua» ${ }^{11}$, «hombres de palos» (p. 36-37); «tinajas ... hombres» (p. 39) y "perros ... caras» (p. 39).

La cruenta dominación de los mayas, así como los tormentos infligidos por los españoles a Tzinacán se ven reflejados por los sacrificios humanos que Tzinacán mismo llevaba a cabo, según éste relata: «Con el hondo cuchillo de pedernal he abierto el pecho de las víctimas y ahora no podría, sin magia, levantarme del polvo» (596). Esto queda avalado históricamente por el investigador de la civilización maya Michael D. Coe: «The supreme sacrifice was human life itself, and all too frequently humans were consigned to be slaughtered in the course of elaborate rituals» ${ }^{12}$. La figura del sacerdote maya encarna así un paralelismo ético de transgresión y castigo. Ha de destacarse, sin embargo, que aunque al parecer Tzinacán no hubiera cometido otra falta que la de negarse a revelar el escondite de cierto tesoro, su yerro consistió en haber oficiado en tales sacrificios humanos. Con toda intención, Borges dejó sin elaborar el móvil de la codicia, puesto que su propósito se encaminó a presentar una problemática ética de mayor complejidad. Dado que si la responsabilidad moral del sacerdote residía únicamente en haber oficiado en unos rituales que no importaban crimen alguno dentro de su cultura; luego, Tzinacán había obrado inocentemente conforme a un canon teológico plenamente sancionado por su sociedad.

Ahora bien: la transgresión de Tzinacán trascendía el mero contexto axiológico de una sociedad determinada, en este caso la quiché, y se remontaba a una esfera de valores éticos universales en la cual el sacrificio humano representaba un delito de lesa vida. Por lo tanto, el mal hado del sacerdote no procedió de su propia civilización, sino que tomó de vehículo a una cultura extraña, invasora y nada exenta ella misma de

${ }^{11}$ Popol-Vuh, trad. de Ralph Nelson (Boston: Houghton Mifflin, 1976), p. 34.

${ }^{12}$ The Maya (New York: Frederick A. Praeger, 1966), p. 106. 
cometer análogos errores. Todo esto convierte a Tzinacán en un héroe verdaderamente trágico, cuya suerte concuerda sencillamente con el concepto aristotélico de hamartia; respecto al cual Butcher ha apuntado que el héroe trágico «falls from a position of lofty eminence; and the disaster that wrecks his life may be traced not to deliberate wickedness, but to some great error of frailty» (Aristotle's Theory, p. 317). Aclarando que «the error is unintentional; it arises from want of knowledge; and its moral quality will depend on whether the individual is himself responsible for his ignorance» (318). Observemos que Borges, por su parte, se abstuvo de emitir juicios morales explícitos. No condenó ni la crueldad del conquistador español ni la de su víctima maya; dejó constancia solamente de su correlación. En el mismo sentido, Aristóteles repudió el criterio estético de Platón de supeditar la poesía a la utilidad moral, e indicó asimismo en su Poética que bastaba con el contexto moral implícito en toda obra literaria (véase Aristotle's Theory, pp. 215-239). Esta abstención de moralizar se extiende a la mayor parte de la obra borgeana conforme, en nuestra opinión, a un entendimiento aristotélico del arte ${ }^{13}$.

El cuento principia con la descripción de la cárcel en que yace prisionero Tzinacán, a fin de sentar el elemento histórico mencionado y dado el susodicho credo aristotélico de Borges, pues siguiendo la idea de que el arte trasciende a lo universal mediante lo particular, la cárcel se eleva de inmediato a un plano simbólico, ya que arquitectónicamente es «profunda y de piedra: su forma, la de un hemisferio casi perfecto, si bien et pesi (que también es de piedra) es algo menor que un círculo máximo, hecho que agrava de algún modo los sentimientos de opresión y de vastedad» (596). Las figuras geométricas que intervienen en la descripción aluden a la esfera y al círculo, símbolos de la divinidad ${ }^{14}$; en este caso sólo se necesita recordar que en «La esfera de Pascal», Borges trazó su evolución simbológica (Otras inquisiciones, p. 636). Sin embargo, la descripción no acomoda un hemisferio ni un círculo perfectos, con lo cual se indica el carácter inescrutable del dios o, lo que es lo mismo, la incapacidad humana de aprehender lo divino se proyecta en las imperfecciones de tales figuras. El que la esfera y el círculo simbolicen la divinidad constituye, como hemos dicho, una concepción secular; pero el que las mismas se apliquen para conformar una cárcel pone de manifiesto una

${ }^{13}$ Es del caso recordar esta declaración de Borges: «Quienes dicen que el arte no debe propagar doctrinas suelen referirse a doctrinas contrarias a las suyas. Desde luego, tal no es mi caso... El escritor debe invalidar con razones humanas la momentánea fe que exige de nosotros el arte» (Otras inquisiciones, p. 698).

${ }^{14}$ Véase J. E. Cirlot, A Dictionary of Symbols, trad, de Jack Sage (New York: Philosophical Library, 1962), pp. 44446. 
premeditación eficaz a los efectos de establecer una relación especial entre Dios y el hombre.

El plano histórico se canaliza por otra característica de dicha edificación: «Un muro medianero la corta; éste, aunque altísimo, no toca la parte superior de la bóveda; de un lado estoy yo, Tzinacán, mago de la pirámide de Qaholom, que Pedro de Alvarado incendió; del otro hay un jaguar que mide con secretos pasos iguales el tiempo y el espacio del cautiverio» (596). La división del recinto en dos vastas secciones enfrenta exclusivamente a un mago y un jaguar. Borges ha recurrido a un símbolo polivalente de gran eficacia para todo el contexto narrativo; nos referimos al jaguar. En efecto, Borges empleó indistintamente el nombre de jaguar o de tigre en la narración con un propósito determinado, cuyo indicio nos viene dado por estas palabras del mago: «Recordé que el jaguar era uno de los atributos del dios» (597). En efecto, en el Popol$V u h$ se le confiere al jaguar origen divino (p. 77); y Tzinacán, sacerdote maya, lo expresa en consecuencia. Mas el jaguar, despojado de esa capa mitológica, y en sentido general de tigre, también es símbolo de la crueldad ${ }^{15}$. La finalidad de Borges es clara: dejar sentada en el jaguar esa calidad siniestra de la divinidad que caracterizará el resto del cuento. Es evidente la correlación entre una divinidad despiadada y una civilización que incluía la esclavitud y los sacrificios humanos, y que manifestaba para entonces serios desarreglos orgánicos, según ha subrayado J. Erick S. Thompson: «The incipient Quiché empire, beset by revolts, collapsed at about the same time as Cocom Mayapán fell. There followed an intensification of intertribal warfare, which, as in Yucatán, ended only with the coming of the white man» ${ }^{16}$. En suma, se reafirma para esta civilización el mismo principio de transgresión y castigo que hemos visto tocante a Tzinacán.

La correspondencia entre la situación precaria de Tzinacán y la célebre alegoría de la caverna de Platón (República, VII) ${ }^{17}$ es demasiado obvia para que se considere una coincidencia, puesto que tanto Tzinacán como los presos del mito platónico permanecen encerrados en la oscuridad e inmóviles y solamente les es dable conocer el mundo de las apariencias. Bordeando la teoría platónica de la anamnesis, por la cual el

${ }^{15}$ Véase José Antonio Pérez-Rioja, Diccionario de simbolos y mitos (Madrid: Tecnos, 1971), p. 401.

${ }^{16}$ The Rise and Fall of the Maya Civilization (Norman: Univ. of Oklahoma Press, 1954), p. 128; véanse, especialmente, pp. 91-130.

${ }^{17}$ Esto lo notó Jaime Giordano sin brindarle desarrollo alguno; véase «Forma y sentido de 'La escritura del Dios' de Jorge Luis Borges», RI, 38 (1972), 111. Para una alusión de Borges a la República, véase «Pascal» (Otras inquisiciones, p. 705). 
alma, presa en el mundo de las apariencias, recuerda su origen divino, Tzinacán narra: «Una noche sentí que me acercaba a un recuerdo preciso... Horas después empecé a visitar el recuerdo: era una de las tradiciones del dios» (596). El sacerdote manifiesta que su dios dejó escrita al principio de la creación una fórmula mágica que conjuraría los males que habrían de sobrevenir al término de los tiempos, y profesa dos creencias: "Consideré que estábamos, como siempre, en el fin de los tiempos y que mi destino de último sacerdote del dios me daría acceso al privilegio de intuir esa escritura» (597).

El mago se entregó entonces a lucubrar qué aspectos revistiría dicha sentencia. El intento es fallido por varios motivos. Unicamente cuando al prisionero de la caverna platónica se le libera por intervención divina, le es dable intentar una percepción más exacta de la realidad. Sin embargo, Tzinacán continúa sumido en su mundo de oscuridad física e intelectiva. Por eso, la incesante rememoración de su saber científico se torna fútil. Por otro lado, Tzinacán ha partido de dos premisas falsas a1 considerar que se hallaba al final de los tiempos y que su destino de último sacerdote del dios era intuir dicha sentencia. Es cierto que la civilización maya se hallaba en estado de decadencia a la llegada de los españoles y que, además, su conquista le asestó el golpe de gracia. No obstante, desde un plano histórico universal, su extinción no representó el fin de los tiempos ni Tzinacán habría de ser el postrer sacerdote del dios, según veremos.

La presunción del sacerdote de creerse un ser elegido pone de manifiesto una falla grave de su carácter, que le acarreará la severa sanción de su dios. El castigo será los sueños que despiertan sucesivamente a otros sueños. Soñó que un grano de arena se multiplicaba en cada sueño hasta colmar la celda y hasta el punto de asfixiarlo. El sentido simbólico de tales pesadillas estriba en el hecho de que el empeño intelectual del hombre por develar el secreto designio de la creación ha de ocasionarle interminable angustia, al tiempo que lo expone a sucumbir exhausto en el laberinto infinito e inexpugnable del mundo de los sentidos, que es, en la terminología platónica, el de la doxa. De modo que la soberbia vino a agravar su suerte mitológica.

Intervino entonces el carcelero, como un deux-ex-machina, abriendo la trampa situada en lo alto de la bóveda: «Un resplandor me despertó. En la tiniebla se cernía un círculo de luz» (598). Huelga decir que resplandor, tiniebla, círculo y luz concuerdan con la simbología divina antedicha y se combinarán posteriormente con otros niveles simbólicos. Se hace patente cada vez más el simbolismo del carcelero, cuya cara se ha ido borrando con el paso de los años y cuyo único menester consiste en 
alimentar al mago y al jaguar desde lo alto de la bóveda. Su función divina es mantener al hombre prisionero de la oscuridad de sus sentidos, permitiéndole, no obstante, el vano laberinto de su memoria e inteligencia, por las cuales éste se ve eternamente incitado a descifrar el enigma inscrito en la naturaleza. Semejante al laberinto de la doxa es el de los sueños, y ambos tienen su correlato en el laberinto de las manchas del tigre, en las cuales creyó Tzinacán que se escondía la escritura de su dios: «Algunas incluían puntos; otras formaban rayas transversales, en la cara interior de las piernas; otras, anulares, se repetían... No diré las fatigas de mi labor. Más de una vez grité a la bóveda que era imposible descifrar aquel texto» (597). Al igual que sucede en el mito platónico, a este preso sólo le será dado extraviarse en las espaciosas imágenes proyectadas por su dios.

Una vez devuelto del mundo de los sueños, Tzinacán exclamó: «Un hombre se confunde, gradualmente, con la forma de su destino; un hombre es, a la larga, sus circunstancias. Más que un descifrador o un vengador, más que un sacerdote del dios, yo era un encarcelado. Del incansable laberinto de sueños yo regresé como a mi casa a la dura prisión. Bendije su humedad, bendije su tigre, bendije el agujero de luz, bendije mi viejo cuerpo doliente, bendije la tiniebla y la piedra» (598). La súbita revelación de sí mismo y de su destino que le adviene al mago responde al concepto de anagnórisis, cuya expresión más simple se formula en la Poética como «a change from ignorance to knowledge» $(1452 a)^{18}$. En fin, esa última tribulación de los sueños llevó al protagonista a realizar un acto de humildad, acatando con resignación el destino inexorable que le había deparado su dios, pues hubo de convencerse de que el encarcelamiento y las privaciones padecidas eran preferibles a la desesperación laberíntica.

No ha de extrañar que el sacerdote experimente entonces el éxtasis místico: "Yo vi una Rueda altísima; que no estaba delante de mis ojos, ni detrás, ni a los lados, sino en todas partes, a un tiempo. Esa Rueda estaba hecha de agua, pero también de fuego, y era (aunque se veía el borde) infinita. Entretejidas, la formaban todas las cosas que serán, que son y que fueron, y yo era una de las hebras de esa trama total, y Pedro de Alvarado, que me dio tormento, era otra. Ahí estaban las causas y los efectos y me bastaba ver esa Rueda para entenderlo todo, sinfín» (598). La visión mística conjuga ciertos elementos antitéticos y paradójicos: agua/fuego, finito/infinito, tiempo/eternidad, víctima/victimario. La Rueda, cuya figura es el círculo (perfecto), contrasta, significativamente, con

${ }^{18}$ L. J. Potts, p. 31. En adelante citaremos por esta traducción de la Poética. 
los símbolos del hemisferio y del círculo imperfectos de la prisión divina. En sentido análogo, tanto la Rueda como la cárcel coinciden en estar conformadas por la antítesis: agua/fuego, hombre/divinidad, respectivamente. De mayor importancia es que la experiencia mística le concedió a Tzinacán la visión del «dios sin cara que hay detrás de los dioses» (599); con lo cual, al paso que se invalida el politeísmo de la religión maya, se propone la unificación en un solo Dios de la pléyade de dioses que adoran los hombres en sus diversas religiones; justificándose asimismo que Tzinacán no pudiera haber sido el último sacerdote del dios, pues su dios representaba solamente una de las caras del Dios único. Incluso el sacerdote alcanzó a entender la escritura del jaguar y, víctima del rapto místico, confesó: «¡Oh dicha de entender, mayor que la de imaginar o la de sentir!» Anteriormente vimos que el esfuerzo intelectual por descrifrar la sentencia divina había sido baldío, mas ahora la razón constituyó el medio de experimentar cabalmente los arcanos divinos: se trata de la razón revelada.

La experiencia mística modificó la dirección narrativa por la revelación de la fórmula de «14 palabras casuales (que parecen casuales), y me bastaría decirla en voz alta para ser todopoderoso» (599). De acuerdo con la peripeteia, que, según la Poética, representa «a reversal in the course of events» (1452a, p. 31), observamos que Tzinacán pasa de un estado de absoluta indefensión a otro de completa libertad de ejercer un poder cuasi-omnímodo. El giro inesperado que toma la acción da paso a la lusis. Borges concluyó sorpresivamente el relato con la declaración de Tzinacán: «Quien ha entrevisto los ardientes designios del universo no puede pensar en un hombre, en sus triviales dichas o desventuras, aunque ese hombre sea él. Ese hombre ha sido él y ahora no le importa. Qué le importa la suerte de aquel otro, qué le importa la nación de aquel otro, si él ahora es nadie. Por eso no pronuncio la fórmula, por eso dejo que me olviden los días, acostado en la oscuridad» (599). Con este final paradójico, Borges procedió también de acuerdo con las pautas genéricas de la cuentística moderna y, concretamente, de la literatura fantástica, dentro de la cual parece inscrita buena parte de su narrativa. A este recurso técnico se ha referido Adolfo Bioy Casares al decir: "The surprise effect may come as a parenthetical revelation, in the way the story is written, or in its ending... Rarely, however, does a writer forgo making use of surprise effects» ${ }^{19}$.

La interpretación del final del cuento ha suscitado diversas opinio-

${ }^{19}$ Adolfo Bioy Casares, "On fantastic literature», Prose for Borges, ed. de Charles Newman and Mary Kinzie (Evanston: Northwestern Univ. Press, 1974), p. 168. 
nes ${ }^{20}$. Nos referiremos a la conclusión de Ana M. Barrenechea, de la cual se ha originado la mayoría de aquéllas: «Borges concludes 'The Writing of the God' by hurling the protagonist from the summit of ecstasy (achieved by his participation in God and the universe) into the most absolute void. ... to become all men, which is equivalent to being no one» (Borges, 89). Debe considerarse que ese ser nadie, que el narrador reclama para sí, expresa que su espíritu ha trascendido la particularidad de ser Tzinacán para alcanzar un estadio inefable de conocimiento y de existencia superiores; lo cual no equivale, en ningún caso, a ser todos los hombres, ni siquiera a identificarse con todos los hombres, como lo han entendido otros críticos. En efecto, el narrador no es nadie desde esa perspectiva cuasi-divina que ha alcanzado. Una vez dicho esto, agreguemos que el otro sí es alguien (esto es, Tzinacán, antiguo sacerdote de la pirámide de Qaholom) para los conquistadores españoles, que aún lo mantienen prisionero, y para el mismo narrador, que, a pesar de que ya no es Tzinacán, según sus palabras, ha narrado retrospectivamente la historia de su nombre. Que lo acontecido a Tzinacán al final del cuento se deba a una desintegración panteísta de la personalidad no lo podemos asegurar; pero tampoco desentonaría con el contexto del cuento y, en general, con el de la obra borgeana ${ }^{21}$.

Borges ha introducido una nota patética al hacer que Tzinacán renuncie a la inmortalidad, al poder y a la libertad y opte por consumirse en su celda. Se trata esencialmente del tema de la libertad, el cual lo personifica Tzinacán dándole un sesgo genuinamente borgeano: un hombre puede ser libre de renunciar a la libertad. Existen, además, otros motivos que explican la actitud del protagonista. Primeramente, su determinación de permanecer cautivo concuerda con un criterio estrictamente platónico. Le dice Sócrates a Glaucon: Una vez que aquellos seres escogidos han alcanzado la contemplación beatífica, «they must be made to descend again among the prisoners in the den, and partake of their labours and

${ }^{20}$ Véase L. A. Murillo, The Cyclical Night: Irony in James Joyce and Jorge Luis Borges (Cambridge: Harvard University Press, 1968) 210-212; Carter Wheelock, The Mythmaker, 127-128; Alberto C. Pérez, Realidad y suprarrealidad, p. 155; Jaime Giordano, «Forma y sentido...», pp. 108-109; Martha Paley de Francescato, «Borges y su concepción del universo en Otras inquisiciones», KRQ, 20 (1973), 475; Lida Aronne Amestoy, "Jorge Luis Borges: La escritura del dios», América en la encrucijada de mito y razón (Buenos Aires: F. García Cambeiro, 1976), p. 167; Eileen M. Zeitz, «'La escritura del dios': Laberinto literario de Jorge Luis Borges», $R I, 43$ (1977), 647-648.

${ }^{21}$ Véase un estudio general del panteísmo en la obra borgeana en el libro de Jaime Alazraki La prosa narrativa de Jorge Luis Borges (Madrid: Gredos, 1968), pp. 60-82. Igualmente, Alberto C. Pérez, pp. 143-156. 
honours, whether they are worth having or not» ${ }^{22}$. Por otra parte, la posibilidad de que Tzinacán rehiciera los acontecimientos históricos de la Conquista hubiera atentado contra la convicción ideológica que Borges dejó expresada en «Nueva refutación del tiempo»: «Cada instante es autónomo. Ni la venganza ni el perdón ni las cárceles ni siquiera el olvido pueden modificar el invulnerable pasado" (Otras inquisiciones, p. 762). Tal vez ello sea una prerrogativa de Dios ${ }^{23}$. En fin de cuentas, una subversión tan grave de los hechos históricos universales hubiera importado asimismo una falla estética totalmente inaceptable para quien ha declarado: «Reality is not always probable, or likely. But if you're writing a story, you have to make it as plausible as you can. ... if you tell an improbable story in an improbable way, it's utterly hopeless» ${ }^{24}$.

Examinemos ahora las convergencias, por demás evidentes, entre la narración y la Cábala. Elemento esencial en la composición de «La escritura del dios» es la problemática lingüístico-metafísica planteada desde el título. A mediados del relato, Tzinacán discurrió que la escritura de su dios podía estar inscrita en la creación: «Una montaña podía ser la palabra de dios, o un río, o el imperio, o la configuración de los astros» (597). Esta concepción panteísta traba perfectamente con el pensamiento cabalístico. Gershom Echolem ha señalado: «In the history of Kabbalism theistic and pantheistic trends have frequently contended for mastery» ${ }^{25}$. Sin embargo, Tzinacán concluyó que ninguna de dichas formas sería lo suficientemente estable para preservar el mensaje divino, ya que «en el firmamento hay mudanza» (597). Obviamente, la idea procede de Heráclito, tal como el mismo Borges lo ha indicado: «Cada vez que recuerdo el fragmento 91 de Heráclito: No bajarás al mismo río, admiro su destreza dialéctica» (Otras inquisiciones, p. 763). En sus continuas cavilaciones, Tzinacán contempla la posibilidad de que «quizá en mi cara estuviera escrita la magia, quizá yo mismo fuera el fin de mi busca» (597). El que Tzinacán mismo pueda ser el objeto de su propia búsqueda tiene su asiento también en el cabalismo. Nos dice Scholem que durante el rapto místico el sujeto «lives through a personal identification with an

${ }^{22}$ The Dialogues of Plato, trad. de B. Jowett (1892; New York: Random House, 1937), I, 778.

${ }^{23}$ Borges declaró en «La otra muerte»: «Modificar el pasado no es modificar un solo hecho, es anular sus consecuencias, que tienden a ser infinitas...; es crear dos historias universales» (El Aleph, 575).

${ }^{24}$ Borges on Writing, ed. Norman Thomas di Giovanny, Daniel Halpern and Frank MacShane (New York: E. P. Dutton, 1973), p. 45.

${ }^{25}$ Major Trends in Jewish Mysticism (Jerusalem: Schocken Publishing House, 1961), p. 22. 
inner spiritual mentor or guru who is revealed to him and who is really Metatron, the prince of God's countenance, or in some cases, the subject's own true self ${ }^{26}$.

La influencia de la Cábala se percibe igualmente en la línea central del argumento. El fracaso de Tzinacán de descrifrar intelectualmente la clave divina de la creación, así como su descripción mediante símbolos de la visión mística, concuerdan con otros señalamientos que Scholem ha hecho sobre el cabalismo: «It seeks an apprehension of God and creation whose intrinsic elements are beyond the grasp of the intellect» (Kabbalah, p. 3). Agregando: «By its very nature, mysticism is knowledge that cannot be communicated directly but may be expressed only through symbol and metaphor» (4). Por lo demás, la concepción de un mensaje divino cifrado en "Cuarenta sílabas, catorce palabras» (599), constituye la esencia misma de la Cábala: «The world process is essentially a linguistic one based on the unlimited combinations of the lettres» (Kabbalah, 25). Anteriormente, Scholem había apuntado que en el Sefer Yezirah «God created the world by means of ' 32 secret paths of wisdom'. This 32 paths, defined as 'ten Sefirot beli mah' and the ' 22 elemental letters' of the Hebrew alphabet, are represented as the foundation of all creation» (23).

Se hace patente que Borges llevó a su cuento esa combinación cabalística de números y de letras para conformar la fórmula cosmogónica que al cabo le fue revelada a Tzinacán. Incluso, la formulación de que «aun en los lenguajes humanos no hay proposición que no implique el universo entero» (597) se ajusta a ese panteísmo cabalístico. La lengua ofrece, por tanto, un laberinto al igual que los laberintos señalados de la doxa, los sueños y las manchas del jaguar. Como bien ha afirmado Enrique Anderson Imbert: «Para Borges, el mundo es caos, y dentro del caos, el hombre está perdido como en un laberinto. Sólo que el hombre, a su vez, es capaz de construir laberintos propios. Laberintos mentales, con hipótesis que procuran explicar el misterio del otro laberinto, ese dentro del cual andamos perdidos» ${ }^{27}$.

Lo humano implica, según Borges, lo múltiple, la multiplicidad propuesta por Platón, y, consiguientemente, la falta de exactitud. Y con los dos mundos del platonismo, el de la doxa y el de las Ideas, la Cábala comparte una concepción igualmente dualista: «The process of creation too has taken place on two planes, one above, and one below, and for this reason the Torah begins with the letter 'Beth', the numerical value

${ }^{26}$ Kabbalah (Jerusalem: Keter Publishing House, 1974), p. 181.

27 Enrique Anderson Imbert, "Un cuento de Borges: "La casa de Arterión'», Jorge Luis Borges, ed. Jaime Alazraki (Madrid: Taurus, 1976), p. 142. 
of which is two. The lower occurrence corresponds to the higher; one produced the upper world (of the Sefiroth), the other the nether world (of the visible creation)» (Major Trends, p. 222). Por eso se contrasta en la narración la limitación espacial y temporal de la celda y el cosmos dilatado del éxtasis. Este dualismo se extiende a otros niveles; así la antinomia de la inmovilidad física de Tzinacán y el dinamismo de su memoria y la potencialidad de trastornar toda la situación tanto a nivel personal como histórico. En sentido análogo se entenderán las series binarias de opósitos que hemos estado constatando. El estatismo o circularidad de la narración radica únicamente en que las circunstancias físicas del final son las mismas que las del comienzo; pero el trance místico - de ahí que éste sea el núcleo del cuento- ha transformado al protagonista.

Incluso esa concepción antitética que entreteje protagonista y antagonista, víctima y victimario, adquiere nítida plasmación en la problemática lingüística de dos lenguajes: el uno divino y el otro humano. Puesto que si al cabo de sus cavilaciones Tzinacán reflexionó que la fórmula divina debía contener «una palabra y en esa palabra la plenitud» (598), la unión mítica le reveló que no se trataba de una palabra, sino de catorce. Tal discrepancia queda implícita en la narración. Acaso deba entenderse que la fórmula revelada no es la de Dios de sí para sí —lingüística divina; esto es, su propio Nombre, sino la de Dios para el hombre, apta exclusivamente para transformar la suerte histórica del mundo y la del protagonista. Trátase, por tanto, de una escritura para un uso antropomórfico determinado -lingüísticamente humana-. En la Cábala profética, por ejemplo, el contenido de la revelación es el Nombre: «This un-veiling of the divine Name through the power of the word is what constitutes the mystical activity of the individual prayer» (Kabbalah, p. 177). Pero ni Tzinacán es un místico en sí, ni tampoco una simple víctima, sino que, como ya se ha indicado, el sacerdote maya es a la vez un victimario. No existía razón alguna para que se le revelara la esencia ontológica del Ser Supremo. Las bases conceptuales en que descansa esta idea fueron formuladas por Borges en su ensayo "Historia de los ecos de un nombre», del cual citamos: «Moisés preguntó al Señor cuál era Su nombre: no se trataba, lo hemos visto, de una curiosidad de orden filológico, sino de averiguar quién era Dios, o más precisamente, qué era» (Otras inquisiciones, p. 751). Huelga concluir que Borges tiene amplio conocimiento teórico del cabalismo ${ }^{28}$.

${ }^{28}$ Esto se hace patente en sus ensayos «Una vindicación de la Cábala» (Discusión, p. 209), «Del culto de los libros» y «El espejo de los enigmas» (Otras inquisiciones, pp. 715, 722, respectivamente). La influencia de la Cábala en la obra de 
La índole de las fuentes que le hemos señalado a la narración apunta con claridad hacia una intención artística definida. La experiencia mística de Tzinacán constituye el núcleo ideológico, linguíístico y narrativo en que se apoya todo el cuento. La visión deífica reviste dos aspectos esenciales: primero, el fenómeno místico en sí, la unión del hombre con la divinidad, y junto a éste, la manifestación cosmogónica que le revela al protagonista la clave y el designio de la creación. Fúndense, así, el plano metafísico con el teológico.

La figura de Tzinacán representa un desdoblamiento de la del propio autor. Borges ha confesado: «La imposibilidad de penetrar el esquema divino del universo no puede, sin embargo, disuadirnos de planear esquemas humanos, aunque nos conste que éstos son provisorios» (Otras inquisiciones, p. 708). No obstante, al concebir «La escritura del dios», le concedió al protagonista la posibilidad de alcanzar dicho esquema divino, que a él, como asiduo estudioso de la metafísica y de la teología, se le había vedado ${ }^{29}$. Se comprende así que Tzinacán, en última instancia, no nos revele la escritura divina ni nos explique cuál sea el designio ulterior de la creación, ni se valga tampoco del poder casi omnímodo por él alcanzado. Todo esto de acuerdo con esa convicción filosófico-teológica de Borges y conforme a otra convicción suya de índole estética: «Esta inminencia de una revelación que no se produce es, quizá, el hecho estético» (Otras inquisiciones, p. 635).

Por último, consignemos que la visión del universo que tiene el personaje Borges en «El Aleph» ha motivado que se hayan relacionado ambos cuentos: «Tutti e due i racconti offrono la similitudine dantesca del poeta visionario che, in estasi, percepisce il mistero e cerca, imperfettamente, di rappresentarlo» ${ }^{30}$. Sería más provechoso, a nuestro entender,

Borges ha incitado algunos magníficos estudios. Véase, sobre todo, el de Jaime Alazraki, «Borges and the Kabbalah», en Prose for Borges, pp. 184-211; Saúl Sosnowski, Borges y la Cábala: La búsqueda del verbo (Buenos Aires: Hispamérica, 1976); Rabi, «Fascination de la Kabbale», L'Herne (Paris, 1964), pp. 265-271.

${ }^{29}$ Manuel Ferrer ha visto la relación entre Borges y Tzinacán desde otro ángulo: «Para el simbólico doble Tzinacán irredento tenemos una nueva faceta, distinta de la Asterión. Borges, como literato, ha construido su universo perfecto tras hallar la clave. Más tarde, asediado y asfixiado por su propia construcción, como hombre ha querido liberarse de la misma, pero habiendo comprendido en su madurez de Tzinacán... que jamás podrá huir, ha decidido resignadamente permanecer para siempre "acostado en la oscuridad' - su ceguedad real-. Como único y desesperado recurso, acudirá al de la venganza sobre su doble literario, que simbólicamente hemos visto en líneas anteriores» (Borges y la nada, London: Tamesis Books, 1971, p. 132).

${ }^{30}$ Stelio Cro, Jorge Luis Borges: Poeta, saggista e narratore (Milano: U. Mursia, 1971), p. 172. 
que se puntualizara la distancia enorme que los separa, cuya diferencia básica estriba en que «El Aleph» está subordinado a una intención esencialmente burlesca y paródica ${ }^{31}$, en tanto que en «La escritura del dios» se propone con toda seriedad artística e ideológica la posibilidad del hecho central narrado.

${ }^{31}$ Martin S. Stabb señaló certeramente la directriz del cuento: «Taken as a halfphilosophical, basically playful composition - generously sprinkled with Borgesian irony and satire - 'El Aleph' comes off rather well» (Jorge Luis Borges, New York: Twayne, 1970, p. 111). 
